\title{
A influência da referencialidade no processamento de orações relativas em português brasileiro
}

\section{The influence of referentiality on relative clause processing in Brazilian Portuguese}

Gitanna Brito Bezerra

Universidade Federal da Paraíba, João Pessoa, Paraíba / Brasil

gitannabezerra@gmail.com

Márcio Martins Leitão

Universidade Federal da Paraíba, João Pessoa, Paraíba / Brasil

profleitao@gmail.com

Lorrane da Silva Neves Medeiros

Universidade Federal do Rio de Janeiro, Rio de Janeiro, Rio de Janeiro / Brasil lorranesnm@hotmail.com

Resumo: Neste artigo apresentamos dois experimentos que foram conduzidos para investigar, no português brasileiro, o papel da referencialidade no processamento de orações relativas associadas a Sintagmas Nominais complexos (SNs complexos) do tipo substância (como "a bolsa de (do) couro"). O experimento de leitura automonitorada revelou uma preferência imediata pela aposição não local, evidenciando uma forte influência da referencialidade do N1 no processamento da oração relativa. O experimento de rastreamento ocular, por sua vez, revelou um efeito imediato da referencialidade do N2: uma aposição local é favorecida quando o N2 é referencial e uma aposição não local é preferida quando o N2 não é referencial. Nossos dados vão na direção do que é proposto pela Hipótese de Construal (FRAZIER; CLIFTON, 1996).

Palavras-chave: processamento; orações relativas; referencialidade. 
Abstract: In this paper we report two experiments that were conducted to investigate the influence of referentiality on the processing of relative clauses associated with complex noun phrases of substance reading (like "the bag of (the) leather"). The self-paced reading task showed an immediate preference for high-attachment, revealing a strong influence of N1 referentiality on relative clause processing. The eyetracking study, in turn, revealed an immediate effect of $\mathrm{N} 2$ referentiality: low attachment is favored when the N2 is referential and high attachment is preferred when the N2 is non-referential. Our data are in tune with the general proposal of the Construal Hypothesis (FRAZIER; CLIFTON, 1996).

Keywords: processing; relative clauses; referentiality.

Recebido em: 9 de dezembro de 2016.

Aprovado em: 31 de janeiro de 2017.

\section{Introdução}

$\mathrm{Na}$ área da Psicolinguística Experimental, diferentes modelos de processamento sentencial buscam explicitar a maneira pela qual os sujeitos compreendem e produzem linguagem. No que tange, especificamente, ao processo de compreensão linguística, tais modelos diferem-se, de forma geral, quanto ao caminho proposto e assumido para se alcançar a interpretação de uma sentença. Nesse âmbito, a Teoria do Garden Path (FRAZIER, 1979; FRAZIER; RAYNER, 1982) propõe que a interpretação de uma sentença pressupõe uma estrutura sintática: o significado de uma sentença vai sendo construído composicionalmente à medida que o parser, o processador sentencial, atribui um esqueleto sintático ao input linguístico. Essa teoria assume, mais especificamente, que o parser, na atribuição inicial de uma representação sintática para uma cadeia linguística, tem acesso restrito à informação sintática, não podendo, por exemplo, acessar de imediato informações discursivas para decidir se apõe um sintagma $\mathrm{X}$ a um local Y ou a um local Z. Decisões desse tipo, oriundas de ambiguidades estruturais, seriam, na verdade, automaticamente feitas seguindo um princípio geral: escolha a primeira análise disponível (FRAZIER, 1987). Uma aposição é imediatadamente determinada, considerando, primeiramente, a análise que pedir o menor número de nós sintáticos (Aposição Mínima) e, no caso de duas análises 
com mesma complexidade estrutural, a análise que implicar uma aposicão ao sintagma ou oração correntemente sendo processado (Aposição Local).

Essa necessária determinação inicial de análise foi repensada quando a Teoria do Garden Path foi reformulada, dando origem à Hipótese de Construal (FRAZIER; CLIFTON, 1996). Uma das motivações para essa reformulação foi o surgimento de evidências experimentais divergentes quanto às predições do princípio da Aposição Local. Em uma sentença como "Alguém atirou no empregado da atriz que estava na varanda", tal princípio prediz uma preferência sistemática pela aposição da oração relativa ao N2, "a atriz", e não ao N1, "o empregado". Porém, em um trabalho seminal, Cuetos e Mitchell (1988) reportaram evidências de que falantes de Espanhol preferiram, na verdade, a aposição ao N1, enquanto falantes de Inglês preferiram a aposição ao N2. A partir de então, este tipo de estrutura com oração relativa passou a ser foco de estudos experimentais em diversas línguas, originando-se diferentes hipóteses na tentativa de explicar a ausência de uma sistematicidade nas preferências de análise entre as línguas (CUETOS; MITCHELL, 1988; GIBSON; PEARLMUTTER; CANSECO-GONZALEZ; HICKOK, 1996; FODOR, 1998, 2002; HEMFORTH; KONIECZNY; SEELIG; WALTER, 2000; MAIA; FERNÁNDEZ; COSTA; LOURENÇOGOMES, 2006; GRILLO; COSTA, 2014; HEMFORTH; FERNANDEZ; CLIFTON; FRAZIER; KONIECZNY; WALTER, 2015).

Nesse contexto, o Construal surgiu reconhecendo a pertinência do princípio da Aposição Local e enfatizando que, antes de dar ênfase às diferenças de aposição observadas entre as línguas e pôr em cheque a universalidade de tal princípio, seria preciso observar as diferentes preferências de análise existentes em uma mesma língua a depender do tipo de estrutura focalizado. Assim, o Construal formalizou uma distinção entre sintagmas primários e sintagmas secundários. O primeiro tipo diz respeito ao sujeito e ao predicado principal de uma oração finita, bem como aos seus complementos e constituintes obrigatórios. O segundo tipo diz respeito aos sintagmas que não podem, nem mesmo temporariamente, ser analisados como sintagmas primários. Os sintagmas secundários ditos "potencialmente primários" terão seu status "primário" acessado em primeiro lugar. Simplificando, o primeiro tipo de relação alude a sintagmas argumentos e o segundo alude a sintagmas adjuntos. A chave dessa distinção é a assunção de que o parser emprega mecanismos de análise distintos dependendo do tipo de estrutura em questão. Dessa 
maneira, diante de uma ambiguidade envolvendo a análise de um sintagma primário, o parser está sujeito a uma pressão para determinar a descrição lexical de um dado núcleo lexical e procede a uma aposição imediata seguindo princípios estruturais - uma análise determinada, então, é automaticamente construída. No entanto, tal pressão não está presente em uma ambiguidade que envolve um adjunto, dado que esse elemento não está envolvido na especificação das propriedades de núcleos lexicais, dando oportunidade para uma indeterminação ou subespecificação inicial de análise - o parser, nesse caso, procede a uma associação.

Com essa distinção feita, Frazier e Clifton (1996) lançaram a hipótese de que o parsing de orações relativas do tipo mencionado anteriormente não exibiria uma sistemática preferência de análise entre as línguas pois ele estaria sujeito à influência não só de informações estruturais, mas também, e crucialmente, de informações não-estruturais. Investigando os fatores que poderiam influenciar o processamento das relativas, os autores propuseram, por exemplo, o Princípio de Referencialidade, segundo o qual orações relativas restritivas são preferencialmente apostas a núcleos referenciais. É este princípio que a presente pesquisa focaliza.

Nós reportaremos dois experimentos em português brasileiro (uma leitura automonitorada e um rastreamento ocular) que realizamos para investigar a influência desta informação não-estrutural de referencialidade. Considerando os resultados obtidos, discutiremos até que ponto os sujeitos deixam-se guiar por informações não-estruturais no processamento on-line e até que ponto eles são sensíveis e fiéis à informação de gênero como material desambiguador. Para embasarmos nossa discussão, organizamos o texto da seguinte forma: no tópico 2, abordaremos a proposta do Construal, apresentando a noção de subespecificação inicial de análise e o princípio da Referencialidade; no tópico 3, apresentaremos os dois experimentos realizados; e, no tópico 4, apresentamos uma discussão geral dos resultados obtidos.

\section{Construal de orações relativas}

A Hipótese do Construal (FRAZIER; CLIFTON, 1996, 1997) para o processamento de sintagmas secundários é a seguinte: associe um sintagma secundário ao domínio de processamento temático (a projeção 
máxima estendida do último atribuidor temático) e o interprete usando informações estruturais e não estruturais. O processo de associação, especificamente, pressupõe a possibilidade de uma subespecificação limitada de análise, já brevemente mencionada, a qual alude ao fato de que, na construção de uma representação sintática, o parser pode deixar relações sintáticas de dominância e irmandade não completamente especificadas. Na figura a seguir, essa indeterminação inicial na análise é evidenciada pela linha tracejada que associa o sintagma secundário XP à estrutura através do $\mathrm{YP}$, que, neste caso, seria a projeção máxima do último atribuidor temático:

FIGURA 1 - Associação de um sintagma secundário

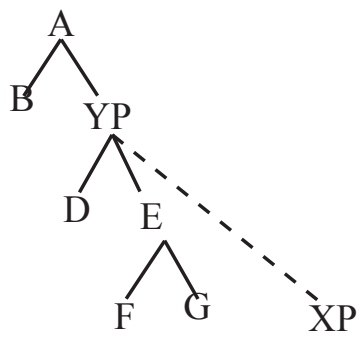

Fonte: Frazier; Clifton (1997, p. 280).

Embora os autores defendam que o parser pode não determinar uma análise estrutural de imediato, a proposição de uma associação inicial a um domínio temático específico garante que o sintagma secundário receba uma estruturação mínima (não ficando, portanto, totalmente sem uma estruturação, "solto", o que, se fosse o caso, afetaria a sua manutenção na memória de trabalho) até que, no processo posterior de interpretação, receba uma análise específica. Considerando a figura 1, no processo de interpretação, o acesso a informações sintáticas e não sintáticas permite que um local determinado de aposição seja selecionado para o sintagma secundário (XP): "If XP associates to YP then XP must take YP, or some node dominated by YP, as its sister" (FRAZIER; CLIFTON, 1997, p. 279). Entende-se, portanto, que, depois da subespecificação inicial, um compromisso sintático é eventualmente realizado, alcançando-se uma representação estrutural com as relações sintáticas devidamente determinadas. 
No tocante, especificamente, aos processos de associação e de interpretação de uma oração relativa, uma informação não estrutural que, no escopo do Construal, é tratada como importante no processo de determinação de análise é a referencialidade do N1 e do N2. De maneira geral, o status referencial de um dado nome relaciona-se ao seu potencial ou não de referir a uma entidade discursiva presente em um modelo discursivo ou de introduzir uma entidade discursiva no modelo discursivo em construção para uma sentença. Com base nesta noção do que seria um nome referencial, Gilboy, Sopena, Clifton e Frazier (1995, p. 136) propõem o Princípio de Referencialidade:

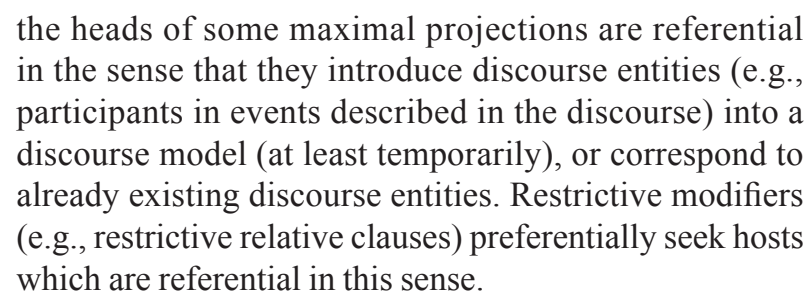

Em específico, os autores assumem que um nome é referencial quando ele é introduzido por um determinante. Seguindo o princípio, se houver, no domínio temático corrente, um nome referencial e um nome não referencial, a relativa será aposta ao nome que é referencial, tendo em vista que ele, correspondendo a uma entidade discursiva, estará disponível para uma modificação restritiva, justificando, assim, a função da oração relativa. Veja-se que este princípio não teria uma predição específica para casos envolvendo sintagmas nominais como "a filha do coronel", já que ambos os nomes se encontram no mesmo domínio temático e ambos são referenciais. O princípio, conforme os autores, poderia prever uma preferência específica para sintagmas nominais como "a mesa de madeira" e "a taça de vinho", sendo o primeiro do tipo "substância" ou "material" e, o segundo, do tipo "quantidade" (ou ainda "conteúdo" e "classificação"). Nesses tipos de sintagmas, é mais natural que o N2 apareça sem um determinante, não sendo, portanto, referencial, sendo todo o SN complexo visto como uma única entidade discursiva. Por consequência, nestes casos, o N1, que é referencial, é visto como o local preferido de aposição da oração relativa.

Gilboy et al. (1995) investigaram, dentre outros fatores, esta influência do status referencial no processamento de orações relativas 
através de dois questionários. Focalizando aqui o SN "substância", foi encontrada, em questionários com falantes de inglês e falantes de espanhol uma preferência geral pela aposição da oração relativa ao N1 em sentenças como "Yesterday they gave me the sweater of cotton that was illegally imported" e (versão em espanhol: "Ayer me regalaron el jersey de algodón que importaban de contrabando"), as quais contêm apenas um nome referencial: o N1. Em um questionário posterior, agora só com falantes de inglês, os autores manipularam a referencialidade do N2, tornando-o também referencial: "Yesterday they gave me the sweater of the cotton that was illegally imported". A predição era a de que a quantidade de respostas $\mathrm{N} 2$ aumentaria neste caso, tendo em vista que o N2 é referencial. De fato, a porcentagem de respostas N2 aumentou de $26 \%$ para um N2 não referencial no questionário anterior para 55\% para um N2 referencial, corroborando, assim, a influência da informação da referencialidade na análise das orações relativas.

O princípio da Referencialidade foi investigado em português brasileiro primeiramente por Maia e Finger (2007). Os autores conduziram um questionário e investigaram a influência de vários tipos de sintagmas complexos no processamente de orações relativas, além de focalizarem a influência de fatores prosódicos nas preferências de aposição. No que tange ao sintagma nominal do tipo substância, os autores investigaram o processamento de sentenças como "O técnico fez críticas à antena de metal que oxida", em que apenas o N1 é referencial, e não manipularam a referencialidade do N2. Os resultados seguiram a linha do que é proposto por Gilboy et al. (1995): diante de um N1 referencial e de um N2 referencial, falantes de português brasileiro prefereriram a aposição da oração relativa ao N1.

Há evidências, portanto, para o princípio da Referencialidade, e elas remetem basicamente ao momento off-line do processamento. Uma questão que aparece, então, neste contexto, é se tal informação poderia influenciar a compreensão on-line da oração relativa, o que remete para uma reflexão mais ampla sobre a natureza dos processos de associação e interpretação assumidos pelo Construal. Veja-se que esta hipótese não propõe um mecanismo de análise específico para o processamento de sintagmas adjuntos, não postulando de forma clara como ocorre o processo de interpretação nem esclarecendo quão persistente seria a subespecificação sintática no decorrer do processamento. É uma questão aberta para o Construal, portanto, quão rápida seria a 
interpretação responsável por conferir uma análise específica ao material subespecificado, o que decorre do fato de não se ter clareza quanto à forma pela qual o parser tem acesso à informação não estrutural que é responsável por determinar uma análise. No processamento de sintagmas primários, em específico, no processo de reanálise, o acesso à informação não estrutural pelo parser é viabilizado pelo processador temático (RAYNER; CARLSON; FRAZIER, 1983; FRAZIER, 1990), que traduz em um vocabulário legível para o parser informações concernentes ao discurso e à plausibilidade, por exemplo. Seria preciso também tornar explícito como o parser enxerga informações não sintáticas que são responsáveis por guiá-lo na determinação de análise de um sintagma secundário (associação $>$ aposição).

Considerando, especificamente, o que poderia conduzir ou encorajar o parser a avançar de uma simples associação para a aposição de um sintagma, Swets, Desmet, Clifton e Ferreira (2008) enfatizam o papel da demanda da tarefa experimental, propondo um diálogo entre a Hipótese de Construal e a Teoria do Good-Enough (FERREIRA; BAYLEY; FERRARO, 2002; FERREIRA, 2003; FERREIRA; PATSON, 2007; KARIMI; FERREIRA, 2015). O fundamento desta teoria é o seguinte: o processamento da linguagem não necessariamente envolve a construção de representações linguísticas acuradas, detalhadas e completas, e isso seria uma decorrência do fato de que, em uma situação real de comunicação, o objetivo do sistema de compreensão não seria produzir representações ótimas a partir de uma computação sintática minuciosa, mas, na verdade, entregar uma interpretação que é apenas boa o bastante (good-enough) para permitir que o sistema de produção gere uma resposta apropriada, contribuindo para o sucesso da interação. Nessa linha de raciocínio, a profundidade de processamento do material linguístico (em termos do grau de comprometimento sintático) estaria relacionada ao objetivo da tarefa na qual os sujeitos estão engajados. $\mathrm{O}$ "good-enough" em situação real de comunicação pode deixar de sê-lo em uma situação de tarefa experimental, por exemplo.

A proposta de Swets et al. (2008) é a de que, posteriormente à associação inicial do sintagma secundário, a busca por informações que auxiliem a resolução da ambiguidade pode ser gradual, podendo se estender ou não até a determinação de uma análise de acordo com os objetivos do leitor. Nesse sentido, na ausência de um material desambiguador e de uma pressão, em termos experimentais, para uma 
aposição específica, a consulta a várias fontes de informação poderia ser apenas superficial. Conforme os autores, a pressão para a realização de uma aposição poderia advir do tipo de questão de compreensão presente em uma tarefa experimental: dada uma ambiguidade quanto à aposição de uma oração relativa, tal como em "Alguém atirou no empregado da atriz que estava na varanda", sujeitos em uma tarefa com questão de compreensão focalizando a oração relativa tendem a realizar uma aposição mais imediata, o que não ocorre no caso de uma tarefa com questão de compreensão superficial, isto é, que não direciona para a interpretação da oração relativa, na qual os sujeitos tendem, em verdade, a deixar uma análise subespecificada.

É importante considerar, no entanto, as críticas tecidas por Frazier (2008) à Teoria do Good-Enough. Conforme a autora, está claro que o objetivo do sistema de compreensão da linguagem não é computar uma representação sintática, mas esta computação seria um meio necessário para se alcançar a mensagem pretendida pelo falante. A sintaxe não seria apenas uma questão de "niceties of high style", mas uma forma de individualizar e acessar entidades e eventos, sem a qual a interpretação poderia ser "a salad of word meanings". Quanto à subordinação do processamento linguístico à demanda da tarefa experimental, a autora questiona a ideia de um controle estratégico da computação sintática e diz que poderia até mesmo não ser apropriado falar em "objetivo" do processador sintático, já que esse seria um sistema de inferência automático. A autora especula, porém, que talvez a fase mais interpretativa do processamento esteja mais aberta a efeitos de profundidade de processamento em dependência da tarefa experimental.

O debate está aceso e o presente estudo insere-se nessa discussão teórica geral na medida em que se propõe a investigar aspectos como: subespecificação inicial de análise e determinação de análise através de informação não estrutural no processamento de orações relativas em português brasileiro.

\section{Experimentos}

Os experimentos realizados por Gilboy et al. (1995) eram de medidas off-line, dando ênfase ao papel da referencialidade no processo de interpretação das orações relativas. Porém, para verificar até que ponto essa informação poderia influenciar o processamento on-line das 
orações relativas, inserindo-se mais diretamente na discussão sobre o grau de subespecificação no processamento sintático que subjaz à noção de associação proposta pelo Construal, optou-se por investigar não só o momento mais reflexivo da compreensão, mas, sobretudo, o momento reflexo. Nesse sentido, apresentaremos a seguir dois experimentos on-line que conduzimos para compreender a natureza do fenômeno em questão.

\subsection{Leitura automonitorada}

Neste experimento, manipulamos a referencialidade do N2 e o gênero do particípio da oração relativa, originando as seguintes condições experimentais:

a) N2 Não Referencial / Aposição ao N1 (N2NR/N1)

O policial apreendeu/ a bolsa de couro/ que foi irregularmente importada/ pela empresa.

b) N2 Não Referencial / Aposição ao N2 (N2NR/N2)

$\mathrm{O}$ policial apreendeu/ a bolsa de couro/ que foi irregularmente importado/ pela empresa.

c) N2 Referencial / Aposição ao N1 (N2R/N1)

O policial apreendeu/ a bolsa do couro/ que foi irregularmente importada/ pela empresa.

d) N2 Referencial / Aposição ao N2 (N2R/N2)

O policial apreendeu/ a bolsa do couro/ que foi irregularmente importado/ pela empresa.

Tomamos como variável dependente o tempo de leitura do segmento três, que contém o material desambiguador, e partimos da hipótese geral de uma influência on-line da referencialidade do N2 e da informação de gênero, assumindo, então, uma preferência geral pela aposição alta da oração relativa quando o N2 é não-referencial mas uma atenuação dessa preferência quando o N2 é referencial, com o gênero do particípio sinalizando essas preferências. Nessa linha, elencamos as seguintes previsões: 
1) tempos de leitura mais lentos em (b) do que em (a);

2) tempos de leitura mais rápidos em (d) do que em (c), pois, em (d), as duas variáveis convergem para a aposição local;

3) tempos de leitura mais rápidos em (d) do que em (b), pois, em (b), o N2 não referencial não favorece a aposição local forçada pelo gênero;

4) finalmente, tempos de leitura mais lentos em (c) do que em (a), pois (c) contém um N2 referencial, que, potencialmente, favorece uma aposição local, mas o gênero guia o parser para a aposição não local.

\subsubsection{Método}

a) Participantes

Participaram voluntariamente do experimento trinta e dois graduandos de universidades estaduais e particulares de Campina Grande (PB) (dos cursos de Direito, Enfermagem e Engenharia Química), todos falantes nativos de Português Brasileiro e com idade média de 21 anos.

b) Material

O material compreendeu quatro conjuntos experimentais, cada um com dezesseis sentenças experimentais e trinta e duas sentenças distratoras: atendendo ao design $2 \times 2$, foram geradas quatro condições experimentais, exemplificadas anteriormente, e, em cada conjunto experimental, foram inseridas quatro sentenças experimentais por condição e o dobro de sentenças distratoras. O modo de distribuição dos itens experimentais em quatro conjuntos respondeu à lógica do design do tipo quadrado latino e do design do tipo intrassujeito, de forma que todos os participantes entraram em contato com todas as condições experimentais, mas não com mais de uma versão de um mesmo item experimental.

No que se refere à estrutura e ao modo de segmentação das sentenças experimentais, elas apresentavam a seguinte estruturação: SN $+\mathrm{V} / \mathrm{SN}$ complexo (N1 de N2) / oração relativa / Agente da passiva. A estrutura do segmento 2 modificava-se entre as condições: nas condições 
N2NR, o N2 não era antecedido por um Determinante, diferentemente do que era observado nas condições N2R. Ainda no que tange ao SN complexo, o N1 e o N2 sempre diferiam quanto ao gênero: quando o N1 correspondia ao gênero feminino, o N2 correspondia ao gênero masculino, e vice-versa. A estrutura do segmento 3, que é o segmento crítico, também se alterava entre as condições: nas condições $\mathrm{N} 1$, o gênero do particípio concordava com o N1, direcionando para a aposição não local da oração relativa, e nas condições N2, o gênero do particípio concordava com o N2, direcionando para a aposição local da oração relativa. O segmento 4 correspondia ao segmento pós-crítico e, também, ao segmento final da sentença. Após este segmento, aparecia, em todos os itens experimentais, uma questão de compreensão, que focalizava a aposição da oração relativa ao N1, tal como "A bolsa foi importada?", para as sentenças mostradas anteriormente. Como a questão focalizava o N1, nas condições (a) e (c), a resposta correta era SIM, e, nas condições (b) e (d), a resposta correta era NÃO.

c) Procedimentos

O experimento foi realizado por meio da técnica on-line de leitura automonitorada na modalidade não cumulativa. Os participantes liam sentenças exibidas de maneira segmentada na tela do computador e apertavam a tecla L para passar de um segmento a outro, respondendo SIM ou NÃO à questão de compreensão que aparecia depois de cada sentença. $\mathrm{O}$ aparato experimental abarcou um Macbook Apple, cujo sistema operacional suporta o programa Psyscope, o qual foi utilizado para programar e rodar o presente experimento.

Nas sessões experimentais, os participantes eram testados individualmente, em uma sala isolada, e recebiam, antes da realização da tarefa, instruções da experimentadora no que tange ao mecanismo geral da tarefa. Além dessa instrução, os sujeitos participavam de uma etapa de prática, na qual entravam em contato com oito sentenças que possuíam estruturas distintas das estruturas das sentenças experimentais. Cada sessão experimental durou cerca de 20 minutos e os sujeitos não reportaram dificuldades na execução da tarefa.

\subsubsection{Resultados}

Os resultados obtidos na análise estatística do segmento crítico não foram coerentes com as previsões: a análise da variância (ANOVA) 
não revelou efeito principal da referencialidade do $\mathrm{N} 2(F(1,31)=0,459$; $p<0,5)$ nem de gênero $(F(1,31)=0,076 ; p<0,7)$, e também não revelou efeito de interação entre as variáveis $(F(1,31)=0,019 ; p<0,8)$. Os tempos médios de leitura podem ser vistos no gráfico 1 :

GRÁFICO 1 - Tempos médios de leitura do segmento crítico

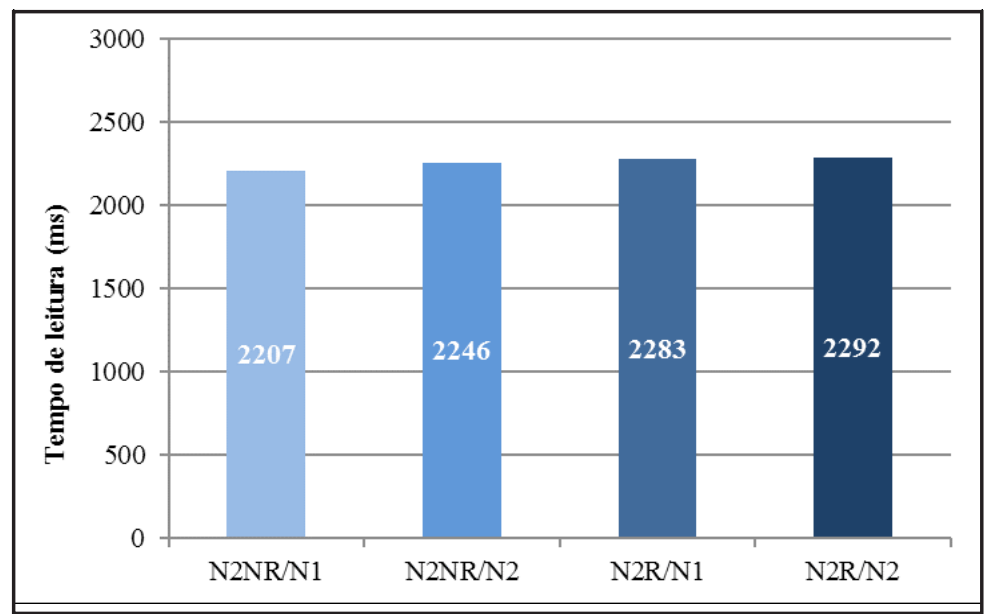

Em busca de um efeito spillover, analisamos os tempos de leitura do segmento pós-crítico. A ANOVA revelou efeito principal de gênero $(F(1,31)=8,34 ; p<0,007)$, evidenciando maiores tempos de leitura nas condições N2 (gênero forçando aposição ao N2), mas não revelou efeito principal da referencialidade do $\mathrm{N} 2(F(1,31)=1,29 ; p<0,2)$ nem efeito de interação entre as variáveis $(F(1,31)=1,51 ; p<0,2)$. Considerando o efeito de gênero, as análises com Teste T revelaram uma diferença significativa apenas na comparação N2NR/N1 vs N2NR/N2 $(t(31)=2,79 ; p<0,008)$, mas não na comparação N2R/N1 vs N2R/N2 $(t(31)=1,28 ; p<0,21)$. Os tempos médios de leitura podem ser vistos no gráfico 2 : 
GRÁFICO 2 - Tempos médios de leitura do segmento pós-crítico / final

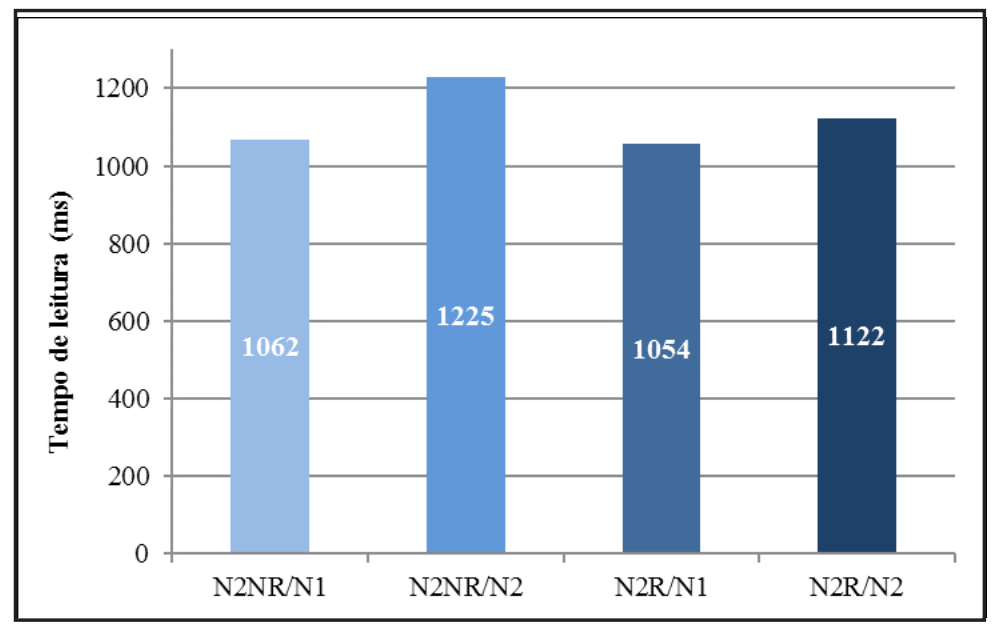

Buscando entender a ausência do efeito de referencialidade do $\mathrm{N} 2$, verificamos, também, o comportamento dos sujeitos diante do SN complexo em si. Comparando os tempos de leitura do SN complexo na condição N2NR com os tempos de leitura do SN complexo na condição N2R, o Teste $T$ revelou que os tempos são significativamente maiores na condição N2R $(t(31)=-2,41 ; p<0,02)$. Esse resultado evidencia que os sujeitos computaram o determinante na condição N2R, embora ele não tenha afetado o processamento da oração relativa subsequente. Os tempos médios de leitura podem ser vistos no gráfico 3: 
GRÁFICO 3 - Tempos médios de leitura do SN complexo

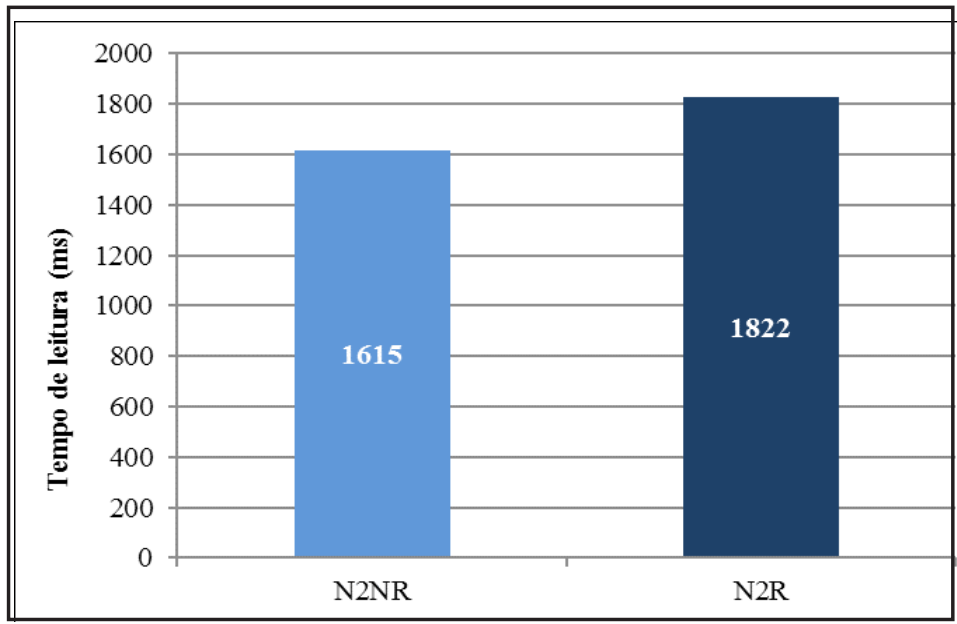

Diante da ausência de efeito da referencialidade do N2 nestes dados on-line, analisamos os tempos de respostas e as respostas à questão de compreensão. Vendo, primeiramente, os tempos de resposta, a ANOVA não revelou efeito principal da referencialidade do N2 $(F(1,31)=0,570 ; p<0,4)$, nem de efeito de interação entre as variáveis $(F(1,31)=0,467 ; p<0,4)$, mas revelou um efeito marginal da informação de gênero $(F(1,31)=3,65 ; p<0,06)$, com efeito marginal emergindo na comparação $\mathrm{N} 2 \mathrm{NR} / \mathrm{N} 1$ vs N2NR/N2 $(t(31)=1,79 ; p<0,08)$, mas sem efeito significativo ou marginal na comparação N2R/N1 vs N2R/N2 $(t(31)=1,12 ; p<0,27)$. Nessa linha, embora de forma não significativa em termos estatísticos, os tempos para responder à questão foram, de modo geral, maiores nas condições N2, como pode ser visto no gráfico 4: 
GRÁFICO 4 - Tempos médios de resposta à questão de compreensão

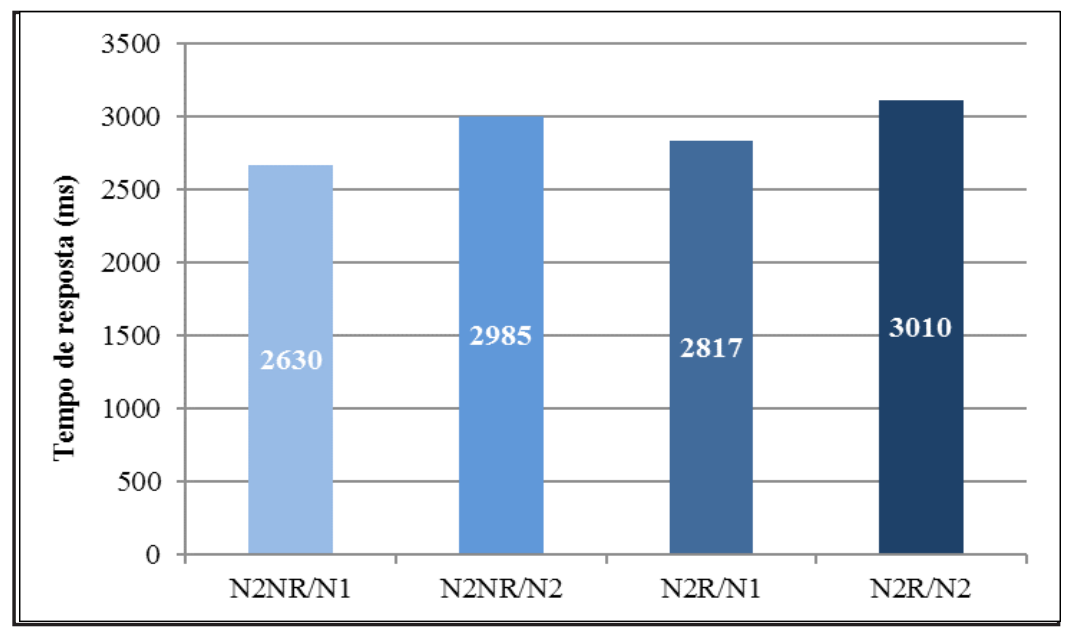

Vejamos o padrão de respostas. Através de testes Qui-quadrado, encontrou-se um número significativamente maior de respostas SIM do que de respostas $\mathrm{NÃO}$ em todas as condições experimentais (N2NR/N1: $X^{2}=91,125 ; p<0,05 ; \mathrm{N} 2 \mathrm{NR} / \mathrm{N} 2: X^{2}=60,5 ; p<0,05 ; \mathrm{N} 2 \mathrm{R} / \mathrm{N} 1: X^{2}=87,78$; $\left.p<0,05 ; \mathrm{N} 2 \mathrm{R} / \mathrm{N} 2: X^{2}=40,5 ; p<0,05\right)$. Vizualizou-se, porém, um efeito principal de gênero $\left(X^{2}=390,94, p<0,0003\right)$, com o gênero forçando a aposição ao N2 aumentando significativamente a probabilidade de respostas $\mathrm{N} 2(\beta=0,7817 ; S E=0,4096 ; z=1,909 ; p<0,05)$. As porcentagens de respostas SIM (N1) podem ser vistas no gráfico 5: 
GRÁFICO 5 - Porcentagem de respostas SIM à questão de compreensão

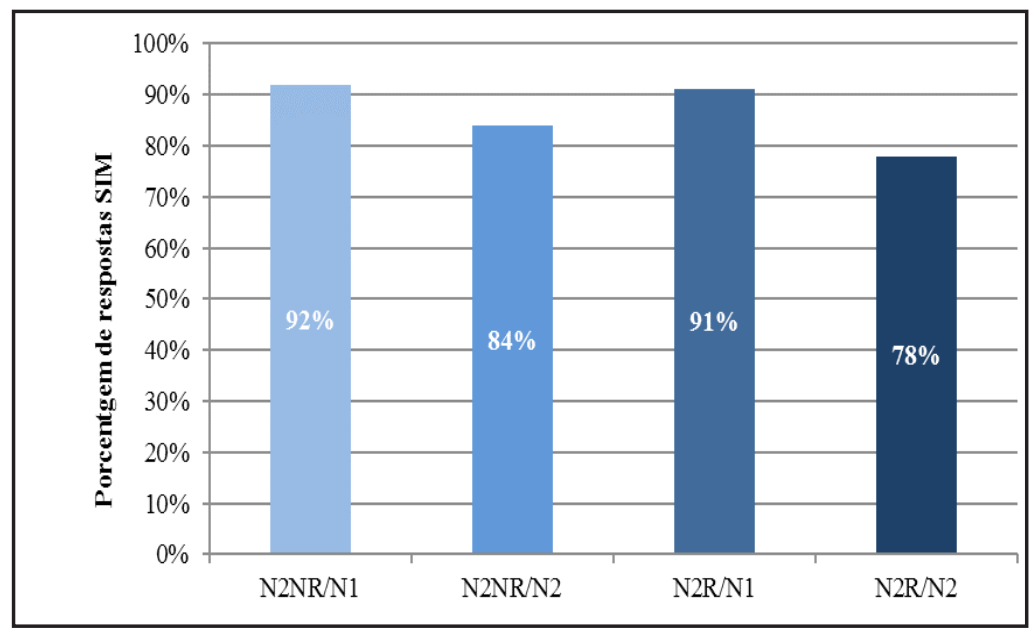

Discutiremos esses resultados no subtópico a seguir.

\subsubsection{Discussão}

Com base nos dados obtidos, vemos que apenas a previsão (1) foi corroborada. Verificamos que, em estruturas com SNs complexos do tipo "substância", não há uma preferência sistemática pela aposição local da oração relativa, em oposição ao que seria predito pelo princípio da Aposição Local (FRAZIER, 1979), mas há uma preferência geral pela aposição não local, já encontrada anteriormente por Gilboy et al. (1995) e Maia e Finger (2007) em uma etapa mais interpretativa da compreensão. Supõe-se que a base dessa preferência de análise tem relação com a natureza semântica do SN complexo "substância". Em SNs como "a bolsa de (do) couro", vemos que a relação entre o N1 e o N2, mediada pela preposição, é a de que "X é feito da substância Y", e essa relação não favorece (ou mesmo bloqueia) a introdução de duas entidades discursivas no modelo mental, favorecendo, na verdade, uma análise em que o $\mathrm{N} 2$ funciona apenas como modificador do N1, ambos correspondendo a uma única entidade discursiva. Os dados sugerem que o parser tem um acesso rápido à restrição imposta por essa relação 
semântica, daí a resistência ${ }^{1}$ que os sujeitos apresentam à construção com N2 referencial.

Tal resistência e a ausência de efeito da referencialidade do N2 indicam que a implicação discursiva da adição do determinante ao N2 (a sua introdução no modelo discursivo como entidade independente do N1 mas a ele relacionado via modificação) não foi a análise imediatamente vista pelo parser. De fato, considerar o N2 como uma entidade discursiva parece requerer um processo mais reflexivo, dado que o artigo definido em si carrega pressuposição (HAWKINS, 1978; HEIM, 1982) e o experimento não contou com contexto prévio. Uma objeção possível seria a de que o N1 também é definido e também está sendo introduzido no modelo discursivo mas, ainda assim, ele é selecionado como local de aposição. Porém, é preciso observar que, no SN complexo em foco, o N1 e o N2 exibem status sintático e semântico distintos. Em termos gerais, o N1 é o núcleo do $\mathrm{SN}$ complexo e é alvo de modificação restritiva, enquanto o N2 justifica sua presença apenas em termos do N1. A nossa hipótese é a de que essa "subordinação" sintático-semântica do N2 (em relação ao N1) pode dificultar o seu processo de acomodação (HEIM, 1982), isto é, pode dificultar a sua introdução no modelo mental em construção para a sentença. O parser, portanto, enxergaria tal subordinação, mas não a dimensão discursiva do N2 referencial.

Reconhecendo essa preferência geral pela aposição não local, devemos refletir, agora, sobre o momento em que ela aparece no curso da compreensão. Para tanto, podemos olhar para o efeito de gênero. Em experimentos psicolinguísticos, o uso de material desambiguador é elucidativo no sentido de poder indicar uma preferência de análise: se uma análise $\mathrm{X}$ foi selecionada em um ponto de ambiguidade, o material desambiguador, quando contrário à análise $\mathrm{X}$ inicial, pode gerar um efeito garden-path e um processo de reanálise, o que causa um maior custo computacional em comparação a um caso em que o material desambiguador apenas corrobora a análise X. No nosso caso, o gênero

\footnotetext{
${ }^{1}$ Nós estamos interpretando os maiores tempos de leitura na condição com N2 referencial como uma resistência pois não se observou um efeito dessa referencialidade no processamento da oração relativa em si. Caso essa influência tivesse sido observada, uma interpretação alternativa seria a de que os tempos estão refletindo um custo associado à inserção e à integração de uma nova entidade no modelo discurso (cf. Warren; Gibson, 2002; Grodner; Gibson; Watson, 2005).
} 
é o responsável pela sinalização de que a análise $\mathrm{X}$, aqui, é aposição ao N1. O efeito de gênero foi encontrado no segmento pós-crítico, que correspondia também ao segmento final, e poderia ser interpretado ou como um efeito spillover de um processamento ocorrido no segmento crítico em si ou como um efeito tardio no sentido de ter sido considerado apenas em uma fase mais final do processamento, talvez como parte de um wrap-up process (JUST; CARPENTER, 1980), que envolve a integração de várias fontes de informação, chegando-se à compreensão final da sentença. Essa discussão se mostra ainda mais pertinente ao se considerar que já existe, na literatura, um debate quanto à sensibilidade do parser a essa informação de gênero, com estudos propondo que ela poderia ser tardiamente acessada (DE VINCENZI; DI DOMENICO, 1999) ou mesmo desconsiderada (BRYSBAERT; MITCHELL, 2000) no processamento. Nesse sentido, o efeito de gênero, por si só, não nos permite dizer, com categoria, se a preferência de aposição ao N1 foi imediata ou se houve uma subespecificação inicial de análise mais prolongada.

Mas se assumirmos que houve uma preferência mais imediata pelo N1, o efeito de gênero poderia ser entendido pelo menos de duas formas, dada a falta de acurácia no padrão de respostas das condições N2 (gênero forçando a aposição ao N2): ele poderia ser o resultado de uma resistência em considerar a possibilidade de apor a oração relativa ao N2 ou poderia ser visto como um sinal de reanálise, mas, nesse caso, de uma reanálise parcial, pois, ao final, é o N1 que acaba sendo majoritariamente escolhido. No âmbito da Teoria do Good-Enough (CHRISTIANSON; HOLLINGWORTH; HALLIWELL; FERREIRA, 2001; RIBEIRO, 2008, 2010, 2012), tem sido considerada a ideia de má interpretação de sentenças garden-path associada com realização de reanálises incompletas, assumindo que o princípio da Composicionalidade, segundo o qual o significado de uma sentença resulta da soma dos significados de suas partes, poderia ser violado no processamento. ${ }^{2}$ Assim, os sujeitos poderiam não ter nem iniciado a reanálise ou tê-la iniciado mas não

\footnotetext{
${ }^{2}$ A Teoria do Garden-Path (FRAZIER, 1979) não assume esta hipótese, defendendo, na verdade, uma construção composicional do significado das sentenças. Nessa linha, após um efeito garden-path, para que a sentença seja devidamente interpretada, é necessário que haja um processo de reanálise pleno.
} 
finalizado, tendo sido o gênero, de qualquer forma, desconsiderado na fase mais final da compreensão, como evidenciado pelas respostas.

Para tentar esclarecer o efeito de gênero e compreender melhor a influência da referencialidade marcada no N2, conduzimos um experimento com rastreamento ocular. Essa técnica é, em geral, caracterizada como mais natural (pela apresentação não segmentada das sentenças, por exemplo) e mais sensível ao processamento sintático inicial em comparação com outras técnicas, como a leitura automonitorada. Acreditamos, portanto, que, por sua própria natureza, o rastreamento ocular possa nos ajudar a esclarecer os dados obtidos neste experimento.

\subsection{Rastreamento ocular}

Neste segundo experimento, manipulamos, também, a referencialidade do N2 e o gênero do particípio da oração relativa. As condições experimentais foram as mesmas do teste anterior:

a) N2 Não Referencial / Aposição ao N1 (N2NR/N1)

O policial confiscou a bolsa de couro que foi importada irregularmente pela empresa.

b) N2 Não Referencial / Aposição ao N2 (N2NR/N2)

O policial confiscou a bolsa de couro que foi importado irregularmente pela empresa.

c) N2 Referencial / Aposição ao N1 (N2R/N1)

O policial confiscou a bolsa do couro que foi importada irregularmente pela empresa.

d) N2 Referencial / Aposição ao N2 (N2NR/N2)

O policial confiscou a bolsa do couro que foi importado irregularmente pela empresa.

Consideramos como região de interesse a forma participial do verbo presente na oração relativa. Como variável dependente, consideramos, inicialmente, o tempo de primeira leitura, que, sendo associada às etapas mais iniciais do processamento sintático, corresponde à soma da duração das primeiras fixações em uma região desde a primeira fixação nessa região até ao seu abandono para a esquerda ou para a direita. 
Partindo da hipótese de um efeito imediato da referencialidade do N2 e do gênero do particípio da oração relativa, fizemos as seguintes previsões:

1) Tempos mais lentos em (b) do que em (a);

2) Tempos mais lentos em (c) do que em (a);

3) Tempos mais lentos em (c) do que em (d);

4) Tempos mais rápidos em (d) do que em (b).

Caso o efeito da referencialidade do N2 e o efeito do gênero não se mostrassem de imediato, poderíamos encontrar as diferenças previstas acima em medidas mais tardias, como no tempo de segunda leitura (que abarca os tempos relativos a todas as releituras da região, incluindo a segunda, a terceira ou e as demais vezes que o leitor entrou nessa região) e no tempo de leitura total (que corresponde à soma dos valores da primeira e da segunda leituras).

\subsubsection{Método}

a) Participantes

Participaram voluntariamente do experimento vinte e oito graduandos da Universidade Federal do Rio de Janeiro, todos falantes nativos de português brasileiro e com idade média de 22 anos. Os sujeitos receberam duas horas em sua carga horária do Curso de Letras pela participação voluntária no teste.

b) Material

Assim como no experimento anterior, o material abarcou quatro conjuntos experimentais, cada um com dezesseis sentenças experimentais (quatro por condição) e trinta e duas sentenças distratoras. O modo de distribuição dos itens experimentais respondeu à lógica do design do tipo quadrado latino e do design do tipo intrassujeito, de forma que todos os participantes entraram em contato com todas as condições experimentais, mas não com mais de uma versão de um mesmo item experimental.

Os itens experimentais tinham a mesma estrutura das sentenças do experimento anterior, com apenas uma modificação: o advérbio foi 
colocado, agora, após o material desambiguador. ${ }^{3}$ Com relação aos itens lexicais, em todos eles, o N1 correspondia ao gênero feminino e o N2 correspondia ao gênero masculino. Após cada sentença experimental, aparecia uma questão de compreensão (focalizando a oração relativa) e duas opções de resposta: N1 e N2, tal como "O que a empresa importou? ( ) Bolsa ( ) Couro", ${ }^{4}$ para os exemplos apresentados. Nas sentenças experimentais, as respostas eram apresentadas sempre com o N1 à esquerda e o N2 à direta; já nas sentenças distratoras, metade das respostas corretas aparecia à esquerda e a outra metade aparecia à direita.

c) Procedimentos

O aparelho utilizado na coleta dos dados foi um rastreador modelo EyeLink 1000, com uma câmera com acurácia de $1000 \mathrm{~Hz}$, configurada para gravação monocular, acoplada a uma tela de 32 polegadas, com resolução de 1920x1080 px. Foi utilizado aparato para a cabeça e a testa do voluntário, enquanto seus movimentos oculares foram gravados durante a leitura das frases. O programa usado para apresentação e registro dos estímulos foi o "EyeTracker $0.7 .10 \mathrm{~m}$ " e a análise foi feita utilizando-se os programas "Robodoc.py" e "EyeDry".

O experimento foi aplicado na sala do Laboratório de Psicolinguística Experimental - Lapex, na Faculdade de Letras da UFRJ. Cada participante era instruído a ler frases, enquanto seus olhos eram monitorados pelo aparelho. Após a instrução da tarefa, o participante era posicionado no equipamento. $\mathrm{O}$ experimentador ajustava a cabeça e a

\footnotetext{
${ }^{3}$ Intuitivamente, achamos que, com a antecipação do material desambiguador, o efeito do gênero poderia ser mais rápido e mais forte. Ferreira e Henderson (1991) propõem, nessa linha, que a distância entre o ponto em que uma análise é atribuída e o ponto em que o material desambiguador aparece pode influenciar a força da análise inicial na memória e, consequentemente, o processo de reanálise: quanto maior a distância, maior a força da primeira análise na memória, o que não favorece a reanálise. Em um estudo de leitura automonitorada (não publicado), fizemos essa alteração, mas nenhuma diferença significativa quanto ao efeito do gênero foi observada.

${ }^{4}$ Respondendo a um dos revisores anônimos: usamos um tipo de questão diferente do utilizado no experimento anterior pois, em um experimento ainda não publicado, encontramos evidências de que o tipo de questão pode influenciar o comportamento dos sujeitos, com uma questão como a do experimento 1 , exemplo, diminuindo a probabilidade de respostas $\mathrm{N} 2$.
} 
testa do voluntário no aparato, pois era importante que o voluntário ficasse com a cabeça imóvel durante a aplicação do teste. Após o devido ajuste, o voluntário tinha a sua pupila calibrada e validada. Nesse processo, o participante era instruído a olhar fixamente para um círculo preto que aparecia inicialmente no centro da tela e movia-se para 9 pontos diferentes. Em seguida, o participante passava pela fase de validação, na qual o aparelho checava todas as fixações oculares capturadas durante a calibragem. Essa fase era de extrema relevância, pois apenas depois da perfeita calibragem e validação da pupila do voluntário era possível continuar com o procedimento.

Antes de cada frase, no canto medial esquerdo da tela, aparecia um quadrado preto indicando que o participante deveria olhar fixamente para este local, para que a frase pudesse surgir na tela. A frase só aparecia se o participante estivesse fixando o olhar no quadrado preto. Isso acontecia sempre antes de cada frase ser apresentada. Após a leitura da frase, o participante era instruído a apertar um botão no joystick (controle), autorizando o aparecimento da questão interpretativa. O participante, então, respondia apertando o botão esquerdo ou direito, e em seguida aparecia um novo quadrado preto, indicando o aparecimento de uma nova frase, e assim por diante. Cada participante realizava a leitura de 96 frases (16 frases experimentais e 32 frases distratoras, com suas respectivas questões interpretativas). Era necessário que o experimentador permanecesse na sala juntamente com o participante, para manuseio do monitor principal, através do qual eram realizados o processo de calibragem e validação, além do aceite das fixações dos voluntários. No processo de aceite das fixações oculares, o experimentador clicava com o mouse sobre a pupila do voluntário, sempre que estava certo de que o participante estava, de fato, olhando para a área correta. Tal procedimento acontecia sempre antes de o quadrado preto surgir e consistia no aparecimento de um círculo preto no centro da tela, onde o participante tinha que olhar fixamente, para que o experimentador pudesse aceitar sua fixação. A duração de cada teste era em torno de 30 minutos. Antes de cada experimento era aplicada uma prática, com o objetivo de treinamento e apresentação da tarefa, com duração de 10 minutos. 


\subsubsection{Resultados}

Focalizando os dados de primeira leitura, a $\mathrm{ANOVA}^{5}$ revelou um efeito principal de gênero $(F(1,99)=8,910 ; p<0,003)$, um efeito principal da referencialidade do $\mathrm{N} 2(F(1,99)=7569,304 ; p<0,001)$ e um efeito de interação das variáveis $(F(1,99)=29,024 ; p<0,001)$. A análise estatística por pares com Teste $\mathrm{T}$ evidenciou como significativas as seguintes comparações: N2R/N1 vs N2R/N2 $(t(99)=28,899 ; p<0,001)$, com a condição N2R/N1 exibindo tempos de leitura maiores; N2NR/N1 vs N2R/ $\mathrm{N} 1(t(99)=-59,700 ; p<0,001)$, com a condição N2R/N1 exibindo tempos de leitura maiores; e N2NR/N2 vs N2R/N2 $(t(99)=64,116 ; p<0,001)$, com a condição N2NR/N2 exibindo tempos de leitura maiores. A comparação $\mathrm{N} 2 \mathrm{NR} / \mathrm{N} 1$ vs N2NR/N2 não revelou uma diferença significativa $(t(99)=-$ $1,291 ; p<0,1)$, havendo, porém, uma diferença numérica na direção esperada. Estes dados mostram a pertinência das previsões (2), (3) e (4) que elencamos anteriormente. Os tempos médios de leitura em cada condição podem ser vistos no gráfico 6 :

GRÁFICO 6 - Tempos médios de primeira leitura de "importado(a)"

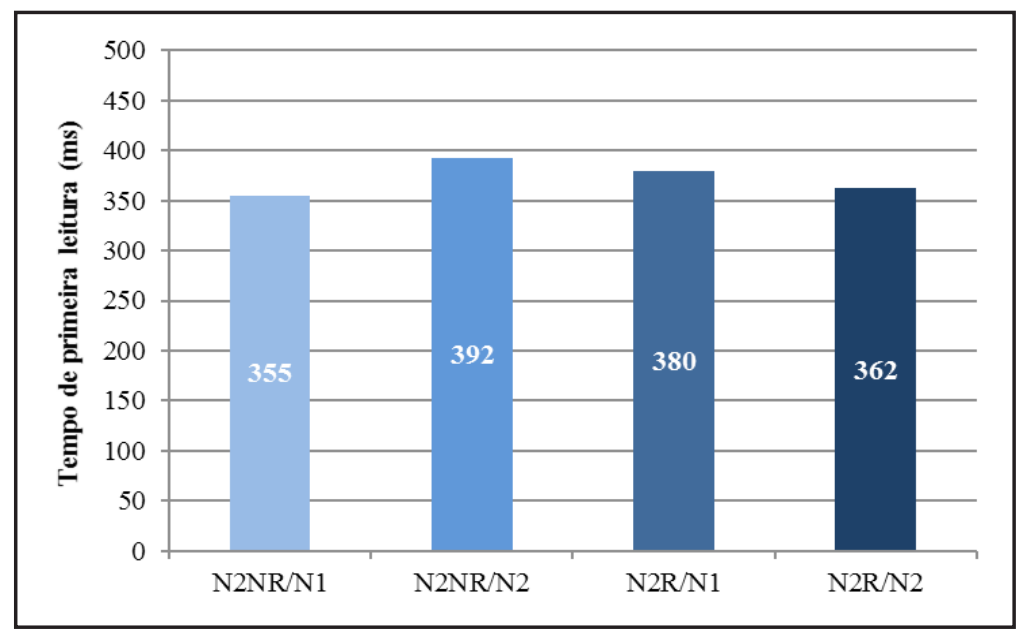

\footnotetext{
${ }^{5}$ Os dados de todas as medidas do rastreamento ocular que consideramos para análise não apresentavam distribuição normal originalmente. Desta forma, para conduzir a ANOVA e o Teste T, procedemos a uma transformação dos dados, o que fizemos por meio do recurso "Transformação Box-Cox" disponibilizado pelo programa estatístico Action.
} 
Analisando os tempos de segunda leitura, a ANOVA revelou um efeito principal de gênero $(F(1,67)=439,432 ; p<0,001)$, um efeito principal da referencialidade do $\mathrm{N} 2(F(1,67)=433,157 ; p<0,001) \mathrm{e}$ um efeito de interação das variáveis $(F(1,67)=422,247 ; p<0,001)$. A análise estatística por pares com Teste T evidenciou como significativas as seguintes comparações: N2NR/N1 vs N2NR/N2 $(t(67)=21,138$; $p<0,001)$, com a condição N2NR/N2 exibindo tempos de leitura maiores; N2R/N1 vs N2R/N2 $(t(67)=1,926 ; p<0,001)$, com a condição $\mathrm{N} 2 \mathrm{R} / \mathrm{N} 1$ exibindo tempos de leitura maiores; e N2NR/N1 vs N2R/N1 $(\mathrm{t}(67)=20,685 ; \mathrm{p}<0,001)$, com a condição N2R/N1 exibindo tempos de leitura maiores. A análise dos tempos de leitura total evidenciou efeito significativo de gênero $(F(1,99)=4,086 ; p<0,04)$ e efeito de interação das variáveis $(F(1,99)=4,857 ; p<0,02)$, com o Teste $\mathrm{T}$ revelando como significativas as seguintes comparações: N2NR/N1 vs N2NR/N2 ( $t(99)=-$ $3,071 ; p<0,002)$, com a condição N2NR/N2 exibindo tempos de leitura maiores; e N2NR/N1 vs N2R/N1 $(t(99)=-2,126 ; p<0,03)$, com a condição $\mathrm{N} 2 \mathrm{R} / \mathrm{N} 1$ exibindo tempos de leitura maiores.

Para entender melhor como os sujeitos lidaram com o N2 referencial em si, decidimos considerar uma segunda região de interesse: o sintagma preposicional (SP) do SN complexo - "de (do) couro", por exemplo. Analisando os tempos de primeira leitura através do Teste $\mathrm{T}$, visualizamos que as condições com N2 referencial geram um custo de processamento maior do que as condições com N2 não referencial $(t(193)=-2,140 ; p<0,03)$, como podemos observar no gráfico 7 : 
GRÁFICO 7 - Tempos médios de primeira leitura do SP

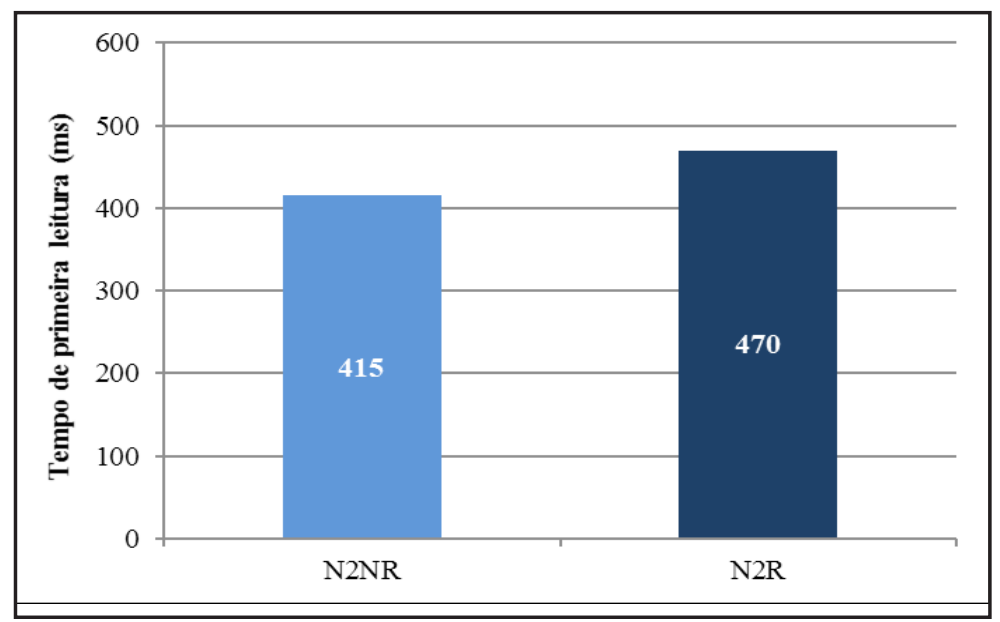

Esse mesmo custo adicional visualizado nas condições N2R apareceu nos tempos de leitura total do SP $(t(193)=-3,815, \mathrm{p}<0,0001)$, mas não nos tempos de segunda leitura $(t(145)=-1,323 ; p<0,1)$.

Finalmente, analisamos, também, os dados das respostas. Quanto aos tempos de resposta, a ANOVA revelou efeito significativo de gênero $(F(1,111)=3428,890 ; p<0,001)$, efeito significativo da referencialidade do N2 $(F(1,111)=3471,358 ; p<0,001)$ e efeito de interação das variáveis $(F(1,111)=2069,417 ; p<0,001)$. A análise estatística por pares efetuada com Teste $\mathrm{T}$ revelou efeitos significativos nas comparações relevantes: N2NR/N1 vs N2NR/N2 $(t(111)=152,373 ; p<0,001)$, com a condição N2NR/N2 exibindo tempos mais lentos; N2R/N1 vs N2R/N2 $(t(111)=52,190 ; p<0,001)$, com a condição N2R/N2 exibindo tempos mais lentos; N2NR/N1 vs N2R/N1 $(t(111)=-52,716 ; p<0,001)$, com a condição N2R/N1 exibindo tempos mais lentos; e N2NR/N2 vs N2R/N2 $(t(111)=-175,743 ; p<0,001)$, com a condição N2NR/N2 exibindo tempos mais lentos. Os tempos médios de resposta podem ser vistos no gráfico 8: 
GRÁFICO 8 - Tempos de resposta à questão de compreensão

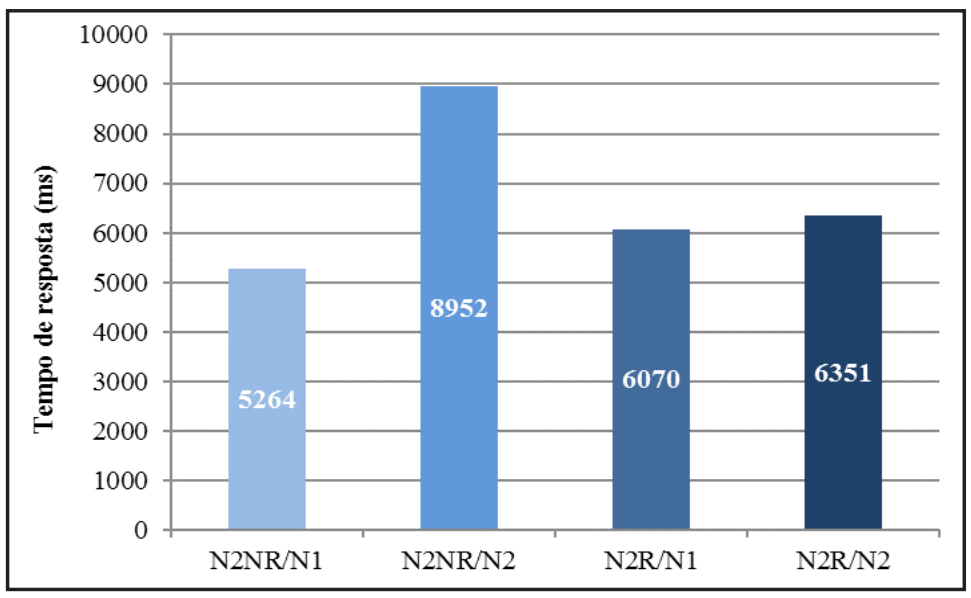

Quanto às respostas em si, testes de Qui-quadrado de aderência revelaram um maior número de respostas $\mathrm{N} 1$ nas condições $\mathrm{N} 2 \mathrm{NR} / \mathrm{N} 1$ $\left(X^{2}=63 ; p<0,001\right), \mathrm{N} 2 \mathrm{NR} / \mathrm{N} 2\left(X^{2}=3,9729 ; p<0,04\right)$ e N2R/N1 $\left(X^{2}=54,32\right.$; $p<0,001)$, não havendo diferença, porém, entre o número de respostas $\mathrm{N} 1$ e N2 na condição N2R/N2 $\left(X^{2}=0,1428 ; p<0,7\right)$. Encontramos, nesta linha, um efeito significativo de gênero $\left(X^{2}=485,01 ; p<0,001\right)$, com a probabilidade de obter uma resposta $\mathrm{N} 2$ sendo significativamente maior quando o gênero força a aposição ao N2 $(\beta=1,5629 ; S E=0,3450 ; z=4,531$; $p<0,001$ ), como podemos observar no gráfico 9 : 
GRÁFICO 9 - Porcentagem de respostas N1 à questão de compreensão

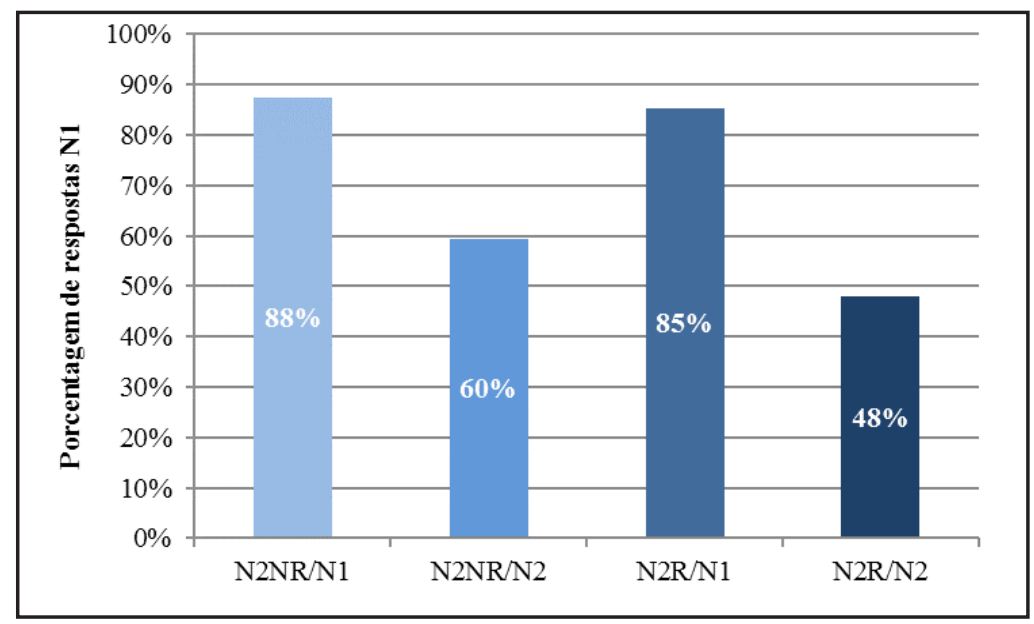

Esse conjunto de dados será discutido no subtópico a seguir.

\subsubsection{Discussão}

Os resultados deste experimento revelaram um efeito imediato do gênero do particípio e da referencialidade do N2: quando o N2 é referencial, há uma preferência imediata pela aposição da oração relativa ao N2, com a condição com gênero forçando a aposição ao N1 causando um maior custo no processamento. Já quando o N2 não é referencial, sugerimos que haveria uma preferência imediata pela aposição ao N1. Nesta linha, a associação inicial proposta pelo Construal (FRAZIER; CLIFTON, 1996) seria rapidamente resolvida, produzindo uma aposição. Esses dados são coerentes com o Princípio da Referencialidade (GILBOY et al., 1995), segundo o qual, em caso de SNs complexos do tipo "substância", a chance de aposição local da oração relativa seria muito maior quando o N2 é referencial do que quando o N2 não é referencial. Considerando a natureza "substância" do SN complexo que estamos focalizando, é interessante refletir sobre o custo adicional encontrado no SN complexo que contém um N2 referencial. No experimento anterior, este custo foi associado a uma resistência a um N2 referencial; porém, nesse segundo experimento, a referencialidade do N2 parece ter influenciado o processamento da oração relativa em si, de modo 
que tal custo poderia ser associado a uma resistência e a uma tentativa de integração do N2 referencial no modelo discursivo. Neste sentido, o custo maior na condição N2R/N1 na região do particípio (encontrado nos tempos de primeira leitura, nos tempos de segunda leitura e nos tempos de leitura total) estaria relacionado justamente à quebra da análise discursiva do N2: considerando que uma sentença como "O policial confiscou a bolsa do couro" não é bem formada em português brasileiro, um N2 referencial nesse tipo de SN complexo só é possível na presença de um modificador restritivo, que seria o responsável por estabelecer o seu referente (cf. Hawkins (1978) para uma discussão sobre casos de "Referent-Establishing relative clauses", isto é, casos em que o SN "pede" uma oração relativa pois ele, sozinho, não consegue introduzir um referente), assim, quando o gênero do particípio bloqueia esta análise, a integração discursiva do N2 fica prejudicada, com ele podendo ser reanalisado como não referencial (o que explica o número equiparável de respostas $\mathrm{N} 1$ nas condições N2NR/N1 e N2R/N1).

Considerando a interpretação acima, precisamos refletir mais sobre dois resultados: o maior custo encontrado na condição N2NR/N2 (sobretudo nos tempos de segunda leitura e nos tempos de leitura total) e o menor custo encontrado na condição N2R/N2 (sobretudo nos tempos de primeira leitura e de segunda leitura). No primeiro caso, a questão é se o custo pode ou não ser associado a um processo de reanálise, já que os dados das respostas revelaram ainda uma preferência pelo N1. É possível que, diante do N2 não referencial, os sujeitos tenham resistido a uma aposição local, realizando o processo de reanálise em alguns itens experimentais, mas em outros não; parece-nos legítimo considerar, também, a possibilidade de o gênero forçando a aposição ao N2 ter instaurado uma "dúvida" no processamento, com os maiores tempos de resposta nesta condição podendo estar associados a uma decisão de análise. Com relação ao menor custo na condição N2R/N2, que estaria relacionado à convergência das variáveis manipuladas, é curioso observar que, apesar da influência on-line da referencialidade do N2, houve um número equiparável de respostas N1 e N2 à questão de compreensão, já que esperávamos um maior número de respostas N2. Uma hipótese, aqui, seria a de que a oração relativa foi, de fato, aposta ao N2 nesta condição, com as respostas evidenciando que esta aposição não elimina a unidade conceitual correspondente ao SN complexo: o processo "a bolsa feita de (do) couro que foi importado irregularmente" implica a unidade-produto 
"a bolsa de couro", e, sendo o couro importado, a bolsa também o teria sido, com este processo inferencial podendo estar associado aos tempos de resposta mais lentos nesta condição.

Os resultados deste experimento são positivos pois evidenciam uma influência imediata dos dois fatores que focalizamos em nossa pesquisa: o gênero do particípio, que tem o potencial de nos revelar uma preferência de análise, e a referencialidade do N2, que nos permite investigar a influência de princípios não estruturais no processamento sentencial. Vimos que o processamento da oração relativa é influenciado pelo status referencial dos nomes que compõem o SN complexo, como predito pelo Construal e pelo Princípio da Referencialidade (GILBOY et al., 1995; FRAZIER; CLIFTON, 1996), e que o processo de subespecificação envolvido no processamento de sintagmas secundários pode ser rapidamente resolvido quando há uma informação útil disponível (no nosso caso, a informação referencial já estaria disponível no $\mathrm{SN}$ complexo em si).

\section{Discussão geral}

Uma questão principal motivou a realização do experimento de leitura automonitorada: a informação não estrutural de referencialidade pode influenciar as decisões iniciais do parser? Os nossos resultados evidenciaram uma preferência geral pela aposição ao N1, com a referencialidade do N2, em particular, não exercendo uma influência na análise da oração relativa. Esses dados não nos permitem dizer, simplesmente, que a referencialidade não influencia o processamento inicial, haja vista que a preferência imediata pela aposição não local observada também residiria na própria natureza referencial do $\mathrm{N} 1$, como defendem Gilboy et al. (1995) para dados off-line, não sendo o fruto da aplicação sistemática de um princípio estrutural. Assim, seguindo o Construal, assumimos que o parser, ao encontrar a oração relativa, procede a uma associação e a apõe, rapidamente, com base na referencialidade do N1.

Duas questões principais motivaram a realização do experimento de rastreamento ocular: (1) a informação de gênero é acessada de imediato pelo parser? e (2) a referencialidade (do N1 e do N2) pode influenciar o processamento inicial da oração relativa? Os resultados permitiram esclarecer, em primeiro lugar, que não há um atraso no 
acesso à informação de gênero, o que nos faz interpretar o efeito de gênero do experimento de leitura automonitorada como efeito spillover, e, em segundo lugar, que a referencialidade do N1 e do N2 influencia o modo de análise da oração relativa: quando apenas o N1 é referencial, a aposição não local seria favorecida, mas quando o N2 é referencial, a aposição local é que seria inicialmente favorecida.

Porém, os dois experimentos revelam, também, que o gênero do particípio e a referencialidade do N2 podem eventualmente ser desconsiderados pelo parser, sobretudo no momento mais interpretativo do processamento sentencial, em favor de uma análise que parece ser a predominante no tipo de estrutura em estudo: a aposição ao N1. Ademais, a diferença entre os experimentos quanto aos resultados da referencialidade do N2 aponta para como o uso de diferentes metodologias experimentais pode ajudar a compreensão de um fenômeno. O modo de apresentação dos estímulos, neste sentido, poderia ter um papel importante: é legítimo cogitar a hipótese de que a não segmentação dos estímulos no rastreamento ocular pode favorecer mais a compreensão e a integração discursiva do N2 referencial do que a segmentação presente na leitura automonitorada, na qual isolamos o SN complexo, aumentando, possivelmente, a resistência ao N2 referencial e favoreceendo uma decisão mais imediata de sua não introdução no modelo discursivo. Por fim, as diferentes medidas fornecidas pelo rastreamento ocular nos permitiram ver com mais clareza o que seria um efeito imediato ou tardio de nossas variáveis.

Em suma, fornecemos evidências de que o processamento de orações relativas associadas a SNs complexos do tipo "substância" é influenciado pela referencialidade dos núcleos que compõem tais SNs. Certamente, precisamos compreender melhor, por exemplo, a resistência ao N2 referencial vista, sobretudo, no primeiro experimento. Já comentamos que a relação sintático-semântica estabelecida entre o N1 e o N2 pode não favorecer a introdução do N2 referencial no modelo discursivo, e estamos trabalhando para alcançar uma explicação mais precisa.

\section{Agradecimentos}

Agradecemos ao professor Marcus Maia pelo seu apoio ao disponibilizar o equipamento e o ambiente físico necessários para a aplicação do experimento de rastreamento ocular. Agradecemos aos dois revisores anônimos pelas contribuições para a melhoria do texto. 


\section{Referências}

BRYSBAERT, M.; MITCHELL, D. C. The failure to use gender information in parsing: a comment on van Berkum, Brown and Hagoort (1999). Journal of Psycholinguistic Research, Springer Link, v. 29, n. 5, p. 453-466, 2000. Disponível em: <https://link.springer.com/article/10. 1023/A:1005191308387>.

CHRISTIANSON, K.; HOLLINGWORTH, A.; HALLIWELL, J.; FERREIRA, F. Thematic roles assigned along the garden-path linger. Cognitive Psychology, Elsevier, v. 42, p. 368-407, 2001. https://doi. org/10.1006/cogp.2001.0752.

CUETOS, F.; MITCHELL, D. C. Cross-linguistic differences in parsing: restrictions on the use of the Late Closure strategy in Spanish. Cognition, Elsevier, v. 30, p. 73-105, 1988. https://doi.org/10.1016/00100277(88)90004-2.

DE VINCENZI, M.; DI DOMENICO, E. A distinction among phifeatures: the role of gender and number in the retrieval of pronoun antecedents. Rivista di Linguistica, Laboratorio de Lingüística Giovanni Nencioni, Pisa, v. 11, p. 41-74, 1999.

FERREIRA, F. The misinterpretation of noncanonical sentences. Cognitive Psychology, Elsevier, v. 47, p. 164-203, 2003. https://doi. org/10.1016/S0010-0285(03)00005-7.

FERREIRA, F.; HENDERSON, J. M. Recovery from misanalyses of garden-path sentences. Journal of Memory and Language, Elsevier, v. 25, p. 725-745, 1991. https://doi.org/10.1016/0749-596X(91)90034-H.

FERREIRA, F.; PATSON, N. D. The 'Good Enough' Approach to Language Comprehension. Language and Linguistics Compass, Wiley Online Library, v. 1, p. 71-83, 2007.

FERREIRA, F.; BAYLEY, K. G. D.; FERRARO, V. Good-Enough Representations in Language Comprehension. Current Directions in Psychological Science, Association for Psychological Science, v. 11, n. 1, p. 11-15, 2002.

FODOR, J. D. Learning to parse? Journal of Psycholinguistic Research, Springer Link, v. 27, n. 2, p. 285-319, 1998. Disponível em: $<$ https://link. springer.com/article/10.1023/A:1023258301588>. 
FODOR, J. D. Psycholinguistics cannot escape prosody. In: SPEECH PROSODY CONFERENCE, 2002, Aix-en-Provence, France. Proceedings of the Speech Prosody, Aix-en-Provence: Laboratoire Parole et Langage, p. 83-88, 2002.

FRAZIER, L. On comprehending sentences: syntactic parsing strategies. 1979. Dissertation (Doctoral) - University of Connecticut, 1979.

FRAZIER, L. Sentence processing: a tutorial review. In: COLTHEART, M. (Ed.). Attention and performance XII: the psychology of reading. Mahwah, NJ: Erlbaum, p. 559-586, 1987.

FRAZIER, L. Exploring the architecture of the language-processing system. In: ALTMANN, G. (Ed.). Cognitive models of speech processing: psycholinguistic and computational perspectives. Cambridge, MA: MIT Press, p. 409-433, 1990.

FRAZIER, L. Is 'Good Enough' parsing good enough? In: ARCURI, L.; BOSCOLO, P.; PERSOTTI, F. (Ed.). Cognition and language: a long story. Festschrift in honor of Ino Flores d'Arcais. Padua: Department of Psychology, University of Padua, p. 13-30, 2008.

FRAZIER, L.; CLIFTON, C. Construal. Cambridge: MIT Press, 1996.

FRAZIER, L.; CLIFTON, C. Construal: overview, motivation, and some new evidence. Journal of Psycholinguistic Research, Springer Link, v. 26, n. 3, p. 277-295, 1997. Disponível em: $<$ https://link.springer.com/ article/10.1023/A:1025024524133>.

FRAZIER, L.; RAYNER, K. Making and correcting errors during sentence comprehension: eye movements in the analysis of structurally ambiguous sentences. Cognitive Psychology, Elsevier, v. 14, p. 178-210, 1982. https://doi.org/10.1016/0010-0285(82)90008-1.

GIBSON, E.; PEARLMUTTER, N.; CANSECO-GONZALEZ, E.; HICKOK, G. Recency preference in the human sentence processing mechanism. Cognition, Elsevier, v. 59, p. 23-59, 1996. https://doi. org/10.1016/0010-0277(95)00687-7.

GILBOY, E.; SOPENA, J.; CLIFTON, C. Jr.; FRAZIER, L. Argument structure and association preferences in Spanish and English complex NPs. Cognition, Elsevier, v. 54, p. 131-167, 1995. https://doi. org/10.1016/0010-0277(94)00636-Y. 
GRILLO, N.; COSTA, J. A novel argument for the universality of parsing principles. Cognition, Elsevier, v. 133, p. 156-187, 2014. https://doi. org/10.1016/j.cognition.2014.05.019.

GRODNER, D.; GIBSON, E.; WATSON, D. The influence of contextual contrast on syntactic processing: evidence for strong-interaction in sentence comprehension. Cognition, Elsevier, v. 95, p. 275-296, 2005. https://doi.org/10.1016/j.cognition.2004.01.007.

HAWKINS, J. A. Definiteness and indefiniteness: a study in reference and grammaticality prediction. London: Croom Helm, 1978.

HEIM, I. The semantics of definite and indefinite noun phrases. 1982. Dissertation (Doctoral) - University of Massachusetts, Amherst, MA, 1982.

HEMFORTH, B.; KONIECZNY, L.; SEELIG, H.; WALTER, M. Case matching and relative clause attachment. Journal of Psycholinguistic Research, Springer Link, v. 29, p. 81-88, 2000. Disponível em: $<$ https:// link.springer.com/article/10.1023/A:1005176507878>.

HEMFORTH, B.; FERNANDEZ, S.; CLIFTON, C.; FRAZIER, L.; KONIECZNY, L.; WALTER, M. Relative clause attachment in German, English, Spanish and French: effects of position and length. Lingua, Elsevier, v. 166, p. 43-64, 2015. https://doi.org/10.1016/j. lingua.2015.08.010.

JUST, M. A.; CARPENTER, P. A. A theory of reading: from eye fixations to comprehension. Psychological Review, Washington, v. 87, n. 4, p. 329-354, 1980. https://doi.org/10.1037/0033-295X.87.4.329.

KARIMI, H.; FERREIRA, F. Good-enough linguistic representations and online cognitive equilibrium in language processing. The Quarterly Journal of Experimental Psychology, Taylor \& Francis, p. 1-28, 2015.

MAIA, M.; FINGER, I. Referencialidade e domínio temático na compreensão de orações relativas curtas e longas em português. Linguística, UFRJ, Rio de Janeiro, v. 3, n. 2, p. 249-278, 2007.

MAIA, M.; FERNÁNDEZ, E. M.; COSTA, A.; LOURENÇO-GOMES, M. C. Early and late preferences in relative clause attachment in Portuguese and Spanish. Journal of Portuguese Linguistics, John Benjamins, v. 6, p. 227-250, 2006. https://doi.org/10.5334/jpl.151. 
RAYNER, K.; CARLSON, M.; FRAZIER, L. The interaction of syntax and semantics during sentence processing: eye movements in the analysis of semantically biased sentences. Journal of Verbal Learning and Verbal Behavior, Elsevier, v. 22, p. 358-374, 1983. https://doi.org/10.1016/ S0022-5371(83)90236-0.

RIBEIRO, A. J. C. A abordagem good-enough e o processamento de frases do português do Brasil. Veredas On-Line, UFJF, Juiz de Fora, v. 2, p. 62-75, 2008.

RIBEIRO, A. J. C. Reanálise parcial de frases garden-path do PB. ENCONTRO NACIONAL DAANPOLL, XXV., 2010. Belo Horizonte: UFMG, 2010. Trabalho apresentado.

RIBEIRO, A. J. C. Late closure e good-enough no processamento de frases garden-path do português do Brasil: evidências de eyetracking. ReVEL, v. 10, n. 18, p. 84-106, 2012.

SWETS, B.; DESMET, T.; CLIFTON, C. Jr.; FERREIRA, F. Underspecification of syntactic ambiguities: evidence from self-paced reading. Memory \& Cognition, Springer Link, v. 36, n. 1, p. 201-216, 2008. Disponível em: <https://link.springer.com/article/10.3758/ MC.36.1.201>.

WARREN, T; GIBSON, E. The influence of referential processing on sentence complexity. Cognition, Elsevier, v. 85, p. 79-112, 2002. https:// doi.org/10.1016/S0010-0277(02)00087-2. 